\title{
CHARACTERIZATION OF A TOPOISOMERASE-LIKE ACTIVITY AT SPECIFIC HYPERSENSITIVE SITES IN THE DROSOPHILA HISTONE GENE CLUSTER
}

\author{
Bryant VILLEPONTEAU
}

Department of Biological Chemistry and The Institute of Gerontology, University of Michigan, 300 North Ingalls, Ann Arbor, MI 48109-2007

Received May 9, 1989

SUMMARY: It is well known that treatment of DNA-topoisomerase complexes with SDS induces cleavage of the DNA by trapping a reactive intermediate in which the topoisomerase is covalently linked to the terminal phosphates of the cut DNA. I have used this technique to examine potential topoisomerase binding sites in the histone gene chromatin of Drosophila $\mathrm{Kc}$ cells. Treatment of $\mathrm{Kc}$ nuclei with SDS induces $\mathrm{Mg}^{++}$-dependent DNA cleavage near the borders of two nuclease-hypersensitive sites located 5' and 3' of histone H4. It is likely that the SDS-induced clcavagc at thcsc hypersensitive sites is due to a topoisomerase because protein becomes tightly bound to the ends of the cleaved DNA fragments. Preliminary experiments suggest that a type II topoisomerase may be responsible for the cleavage.

(-) 1989 Academic Press, Inc.

DNA topoisomerases appear to be ubiquitous in nature. In prokaryotic cells topoisomerases are involved in most chromosomal functions including transcription, replication, and recombination (for reviews, see refs. 1-3). Less is known about the functions of eukaryotic topoisomerases but many studies have suggested that they play important roles in transcription, replication, and the maintenance of active chromatin structure (412).

The data indicating that topoisomerases act selectively in transcribed domains (4-10) support the hypothesis that topoisomerases are normally directed to specific regulatory sites in the chromatin near transcribed genes. Likely loci of topoisomerase action in vivo are nuclease hypersensitive sites, which are often found near expressed genes (13) and which may be under torsional stress (14-16). A type II topoisomerase has been shown to cleave within the large nuclease hypersensitive region of SV40 chromatin (17), suggesting a role for topoisomerase II at hypersensitive sites.

One standard method for detecting topoisomerase binding sites in vitro is to induce topoisomerase to cleave DNA (18-22). Topoisomerases act via a strand passage mechanism whereby transient breaks are introduced into DNA. In the presencc of $\mathrm{Mg}^{++}$, SDS denaturcs and traps the topoisomerase-DNA complex in a cleaved state in which the topoisomerase is covalently linked to the terminal phosphate of the cut DNA (18-22).

To search for possible in situ topoisomerase binding sites in chromatin, I have searched for SDSinduced cleavage within the repeated histone gene cluster of Drosophila $\mathrm{Kc}$ cells. In vitro studies (22) have shown that SDS induces purified Drosophila topoisomerase II to cut cloned histone gene plasmids at defined 
sites close to the $5^{x}$ and 3 boundaries of the genes. Here I report that an cndogenous topoisomerase II-like activity cleaves a small subset of these same sites within nuclei of Drosophila Kc cells.

\section{MATERIALS AND METHODS}

\section{Preparation of nuclei}

Drosophila $\mathrm{Kc}$ tissue culture cells were grown in suspension cultures at $23^{\circ} \mathrm{C}$. Cells were pelleted and resuspended in $\mathrm{RSB}_{\mathrm{gs}}(10 \mathrm{mM}$ Tris- $\mathrm{HCl}, \mathrm{pH} 7.4,10 \mathrm{mM} \mathrm{NaCl}, 3 \mathrm{mM} \mathrm{MgCl}, 0.3 \mathrm{M}$ sucrose, $40 \%$ glycerol, and $0.4 \%$ NP40) which lyses the cells. After incubation for 2 minutes on ice, the nuclei were pelleted for 5 minutes at $2,500 \times \mathrm{g}$ and then resuspended in cold $\mathrm{RSB}_{\mathrm{gs}}$ without NP40 at a DNA concentration of $500 \mu \mathrm{g} / \mathrm{ml}$.

\section{SDS-induced DNA cleavage}

Nuclei in $\mathrm{RSB}_{\mathrm{gs}}$ were treated with $0.5 \%$ SDS and incubated for various times at room temperature. The SDS-induced cleavage is stopped by adding $20 \mathrm{mM}$ EDTA. Rapid isolation of nuclei is essential for obtaining efficient SDS-induced topoisomerase-mediated cleavage, as isolated nuclei soon lose the capacity for SDSinduced cleavage.

\section{Isolation of DNA and DNA-protein complexes}

Protein free DNA was isolated from SDS- and EDTA-trcatcd nuclei using overnight protease $\mathrm{K}$ digestion $\left(100 \mu \mathrm{g} / \mathrm{ml}\right.$ at $\left.37^{\circ} \mathrm{C}\right)$ followed by two phenol-chloroform (1:1) extractions, two ether extractions, and ethanol precipitation. To isolate DNA-protein complexes, nuclei in RSB containing $0.5 \%$ SDS and $20 \mathrm{mM}$ EDTA were made $4 \mathrm{M}$ in urea and run through a sepharose CL-6B column (Pharmacia) to rid them of urea, SDS, and non-covalently bound proteins.

\section{Other methods}

Isolated DNA and DNA-protcin complexes wcre digested with BglII or BamH1 (Bethesda Research Laboratories) and run on a $1.2 \%$ agarose gel in Tris-acetate buffer. The gel was Southern blotted (23) and the nitrocellulose blot hybridized $(24)$ to a [ $\left.{ }^{32} \mathrm{P}\right]-$ labeled nick-translated BamH1-BgIII fragment from the H1 histone gene.

\section{RESULTS}

\section{DNA cleavage at hypersensitive sites by a topoisomerase-like protein}

If a Drosophila topoisomerase II acts site-specifically in vivo, then SDS treatment of properly prepared nuclei should induce site-specific, $\mathrm{Mg}^{++}$-dependent, double-stranded cleavage of the nuclear DNA. I have examined the histone domain of Drosophila Kc cells for such cleavages. To minimize structural damage to the nuclei and to maximize retention of bound topoisomerase, nuclei from $\mathrm{Kc}$ cells were rapidly isolated in a gentle one-step centrifuge spin using cold lysis buffer containing low salt and high glycerol concentrations. The nuclei were then lysed with $0.5 \% \mathrm{SDS}$ and incubated at room temperature in the presence of $3 \mathrm{mM} \mathrm{Mg}^{++}$. At various times, EDTA was added to stop the cleavage reaction. The DNA was deproteinized using protease $\mathrm{K}$ and phenol, electrophoresed on an agarose gel, Southern blotted, and analyzed by indirect end-labeling with an H1specific probe.

Fig. 1A shows the kinetics of the SDS-induced DNA cleavage (SDS was added at 0 minutes) as a function of the time when EDTA was added to stop the reaction. Following incubation in $\mathrm{Mg}^{++}$and SDS (10 to 90 minute lanes in Fig. 1A), double-stranded DNA cleavages were induced near the 5 ' ends of the $\mathrm{H4}$ gene as well as at site " $\mathrm{C}$ " which is located 3' of histone $\mathrm{H4}$. These cleavages are within known hypersensitive sites in the histone gene cluster (25). The $\mathrm{Mg}^{++}$-dependence of the SDS-induced cleavages is further shown in Figs. 1B and 1C. The SDS-induced cleavages were only observed when EDTA was added 10 minutes after the addition of SDS (lanes 2). The double-stranded mode of cutting and the dependence on SDS and $\mathrm{Mg}^{++}$suggest that these cleavages are mediated by a type II topoisomerase $(1,18-20)$. Furthermore, the observation that cleavage does not increase with incubation time in SDS but reaches a maximum within the first 10 minute time point (Fig. 1A) is consistent with the expected pattern of topoisomerase II cleavage (20). 
A

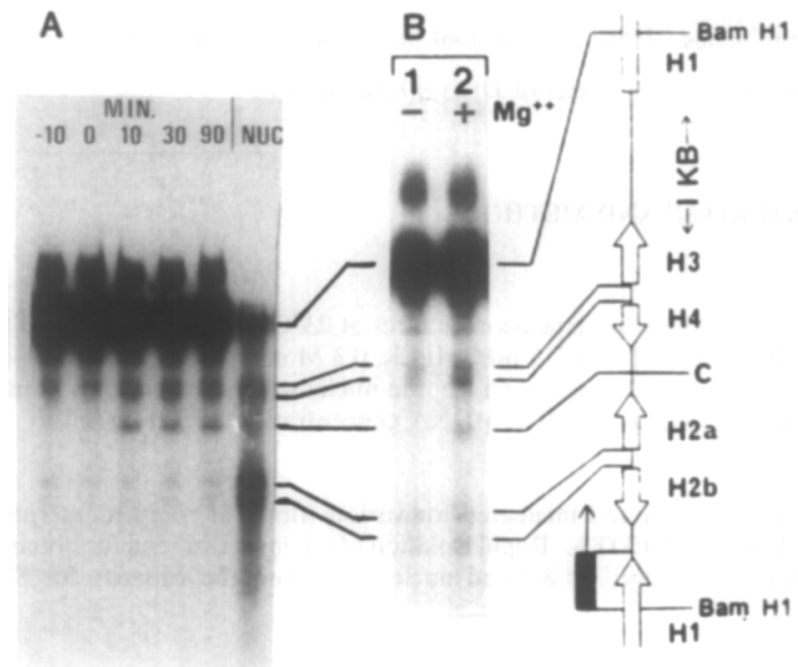

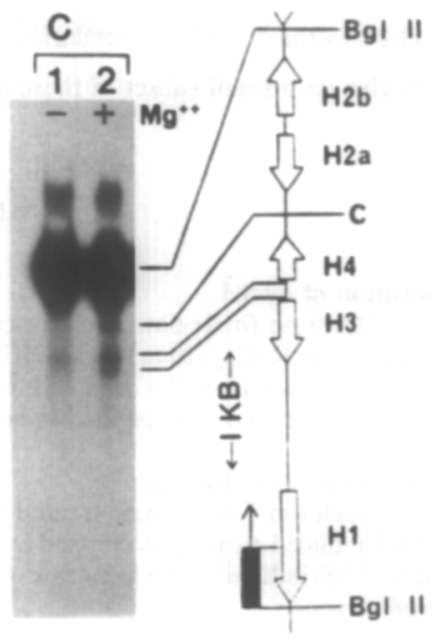

Flgure 1. SDS induces $\mathrm{Mg}^{++}$-dependent DNA cleavage in the histone gene cluster

A. $0.5 \%$ SDS was added to cold Drosophila $\mathrm{Kc}$ nuclei at 0 minutes and the nuclei incubated at room temperature for 90 minutes. To stop the SDS-induced cleavage reaction, $20 \mathrm{mM}$ EDTA was added 10 minutes before SDS (lane 1), simultaneous with SDS (lane 2), or 10 to 90 minutes after SDS addition (lanes 3-5). DNA was isolated, restricted with $B a m \mathrm{H} 1$, and electrophoresed on agarose gels. Following Southern transfer (23), the nitrocellulose blots were hybridized to a $\left.{ }^{32} \mathrm{P}\right]$-labeled nick-translated $B a m \mathrm{H} 1-B g$ III fragment from the $\mathrm{H1}$ histone gene and autoradiographed. Lanc 6 contains DNA purified from nuclei cleaved with endogenous nuclease. B and C. The $\mathrm{Kc}$ nuclei were treated with $0.5 \%$ SDS (lanes 2 ) and incubated at room temperature for 10 minutes before the addition of EDTA. In lanes 1, EDTA was added prior to the addition of SDS and then the nuclei were incubated at room temperature for 10 minutes as in lane 2. The purified DNA was restricted with $B a m H 1$ (B) or BglII (C) and was probed.

The most diagnostic indicator of authentic SDS-induced topoisomerase-mediated DNA cleavage is the covalent linkage of the topoisomerase to the DNA through a phosphodiester bond (18-22). To test whether SDSinduced cleavage leads to the covalent attachment of protein to the Drosophila histone DNA, nuclei were treated with SDS-Mg ${ }^{++}$as before and the nuclear DNA was purified free of SDS and non-covalently attached proteins by the addition of urea and gel filtration through a sepharose CL-6B column. The isolated DNA samples were cut with restriction enzyme and half of each DNA sample was digested with protease $K$. The samples were then electrophoresed on an agarose gel, Southern blotted, and hybridized to the labeled $\mathrm{H} 1$ probe as before.

The DNA bands corresponding to SDS-induced DNA breakage at the $\mathrm{H} 4$ and $\mathrm{C}$ sites are seen at their normal positions if protease $\mathrm{K}$ treatment is used (Fig. 2, lanes 2). However, when protease $\mathbf{K}$ is omitted (Fig. 2, lanes 1), these bands disappear (band " $\mathrm{C}^{\prime \prime}$ ) or are reduced in intensity (the 5 ' $\mathrm{H4}$ band) as expected for the altered mobility of protein-attached DNA $(17,19)$. To show that these results are not due to cleavage by endogenous nucleases, nuclei were isolated and allowed to autodigest in the presence of $\mathrm{Mg}^{++}$but in the absence of SDS for 1 hour. This resulted, as expected, in cleavage at the H1, H2A-H2B, C, and H3-H4 hypersensitive sites by an endogenous nuclease (Fig. 2, lanes 4). However, the mobilities of these fragments did not change when protease $\mathrm{K}$ treatment is omitted (lanes 3 ).

Another indication of a type II topoisomerase-mediated cleavage is the covalent linkage of the enzyme to the 5 ' end of the DNA, leaving a free 3 ' hydroxyl (18-20). To test whether the SDS-induced breaks have unblocked 3' ends, the cleaved DNA was digested with 3'-specific exonuclease III. The DNA was then protease $\mathrm{K}$ digested, cut with restriction enzyme, and analyzed as before. The SDS-cleaved DNA was reduced in size 

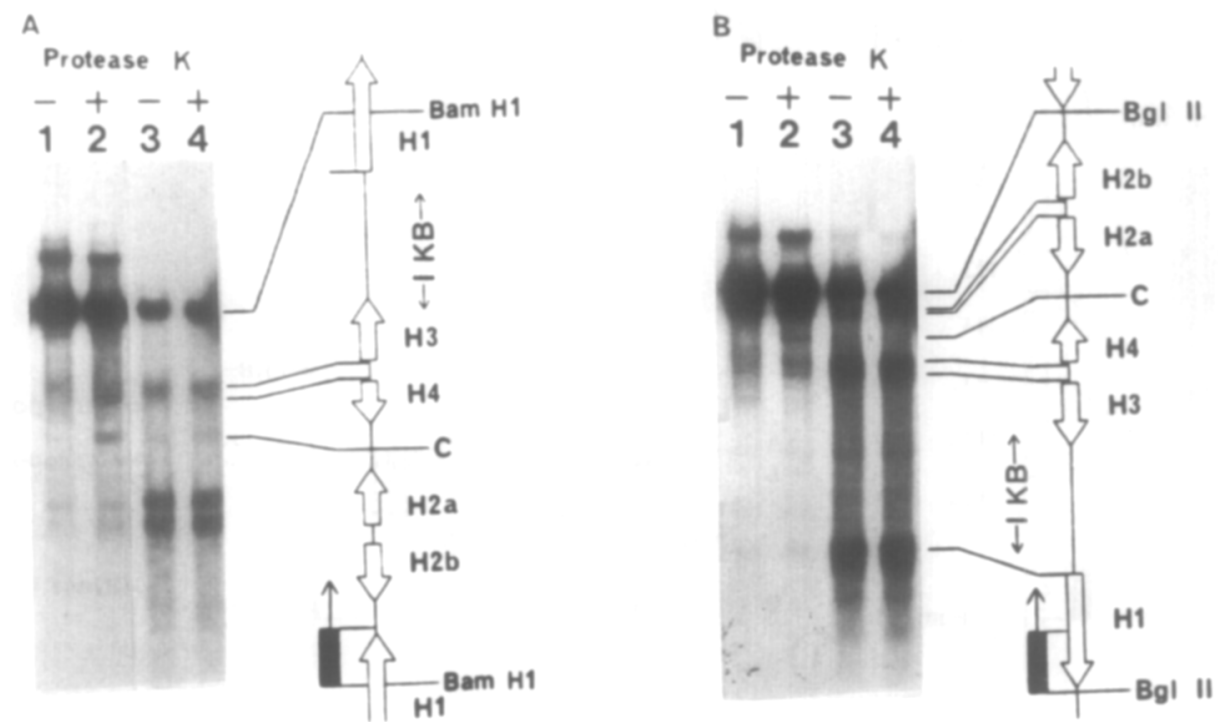

Figure 2. SDS-induced cleavage is accompanied by attachment of protein to the DNA

Kc nuclci in RSB ${ }_{\text {gs }}$ were madc $0.5 \%$ in SDS (lancs 1,2 ). After 10 minutes, EDTA and urea were added to 20 $\mathrm{mM}$ and $4 \mathrm{M}$. As a control, some nuclei were allowed to autodigest with endogenous nuclease for 60 minutes (lanes 3 and 4) before stopping the digestion with EDTA and SDS-urea. DNA-protein complexes were isolated as described in Materials and Methods. The DNA samples were then restricted with BamH1 (A) or BglII (B). One half of each DNA sample received protease K (lanes 2,4$)$ before agarose gel electrophoresis.

following digestion with exonuclease III (Fig. 3), demonstrating the existence of free 3' termini. Thus, the protein-DNA covalent linkage is presumably at the 5 ' end.

The above results show that SDS-induced cleavage in the Drosophila histone domain has the diagnostic characteristics of topoisomerase-mediated cleavage. $\mathrm{Mg}^{++}$-dependence, double-stranded DNA cutting, and the existence of free 3 ' ends are most consistent with cleavage by a type II as opposed to a type I topoisomerase (1822). Thus, the $\mathrm{H} 4$ and " $\mathrm{C}$ " hypersensitive sites within Drosophila histone chromatin appear to be loci for the in situ binding of topoisomerases II.

\section{DISCUSSION}

Many lines of evidence implicate topoisomerases in eukaryotic gene expression (4, 5, 7-12). Since it is likely that genetic functions that involve alterations in the structure of the chromatin fiber would require topoisomerases, I have attempted to identify in situ sites of topoisomerase binding. To approach this problem, Drosophila nuclei were treated with SDS with the intention of trapping topoisomerase-DNA complexes in situ via the induction of DNA breaks. These cleavage sites were localized in the histone gene cluster by indirect endlabeling and a map prepared as is shown in Fig. 4 (down arrows). $\mathrm{Mg}^{++}$and SDS are required for the reaction, the cleavage is double-stranded, and protein appears to be attached to the $5^{\prime}$ end of the DNA. These are the known characteristics of the abortive strand-passage reaction mediated by topoisomerase II (18-22). However, in the absence of definitive antibody data, the conclusion that the cleaving enzyme is a type II topoisomerase should be viewed as preliminary, since a type I topoisomerase with some of the same properties has been found to cleave within a hypersensitive site located 5 ' of the rDNA gene in Tetrahymena (26).

The SDS-induced DNA cleavage reported here differs markedly from cleavage by endogenous nucleases. First, the pattern of endogenous nuclease cleavage is nearly identical to that found with pancreatic DNase I (Figs. 

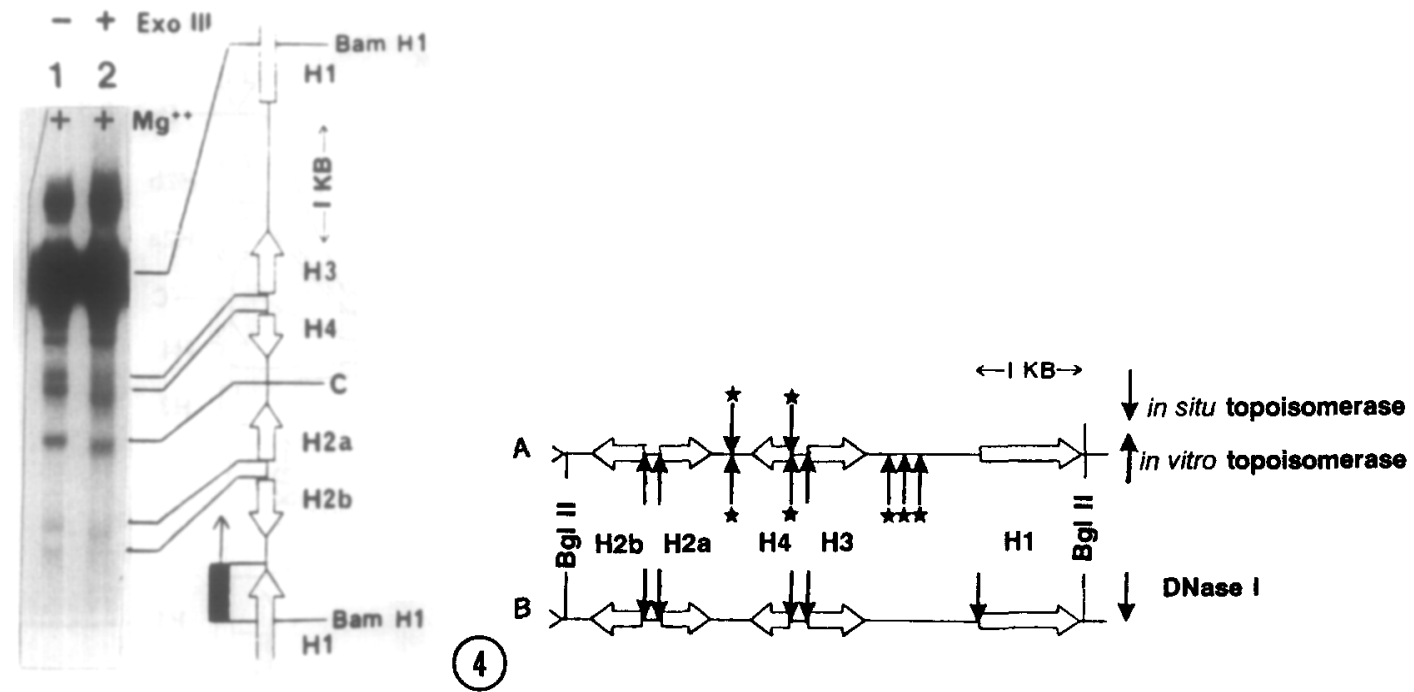

Fiqure 3. SDS-cleaved DNA has a free 3' OH

$\mathrm{Mg}^{++}$-dependent SDS-cleaved DNA was purified from Drosophila nuclei treated with SDS and $3 \mathrm{mM} \mathrm{Mg}^{++}$ as described in Fig. 1. $5 \mu \mathrm{g}$ of cleaved DNA was incubated with (lane 2) or without (lane 1) 15 units of exonuclease III before restriction with BamHI.

\section{Figure 4. Topoisomerase II and nuclease cleavage maps}

A. In situ and in vitro sites of SDS-induced topoisomerase II-mediated DNA cleavage were mapped. Down arrows are drawn from the in situ SDS-induced cleavage of Drosophila Kc nuclei as determined in Figs. 1 and 2. Up arrows are drawn from data on the in vitro SDS-induced cleavage of cloned histone DNA with purified Drosophila topoisomerase II (22). The strongest sites are starred. B. Sites of DNase I cleavage (down arrows takcn from my unpublished data and from reference 25). Endogenous nuclease yields a cleavage pattern identical to that shown for DNase $I$.

$1 \mathrm{~A}$ and 2 and ref. 25) but markedly different from the SDS-induced cleavage pattern (Figs. 1-4). The most prominent SDS-induced cut (the " $\mathrm{C}$ " site) is only a very minor cleavage site in nuclei allowed to autodigest with endogenous nuclease. Moreover, the prominent endogenous nuclease cleavage site located 5 ' of $\mathrm{H} 1$ is completely absent with SDS-induced cleavage (Figs. 1C and 2B). Second, the SDS-cleaved but not the endogenous nucleasecleaved DNA fragments migrate differently on agarose gels when covalently attached protein is not removed by protease $\mathrm{K}$ (Fig. 2), indicating that proteins do not become covalently attached during cleavage by endogenous nuclease as is the case with the SDS-induced cleavage. Third, no nucleases have been characterized which remain active following denaturation by $0.5 \%$ SDS, indicating that the SDS-induced activity can not be a common nuclease.

Figure 4 compares the putative in situ topoisomerase interaction sites with the in vitro topoisomerase II sites reported by Udwardy et al. (22), who used purified Drosophila topoisomerase II and naked plasmid DNA to map SDS-induced type II topoisomerase-mediated cleavage sites. Within the limits of the resolution of the gels, the two in situ nuclear SDS-induced cleavage sites both map to observed in vitro topoisomerase II cutting sites (see Fig. 4A). However, the three strongest in vitro topoisomerase II cleavage sites (found 3 ' of H3, see ref. 22) are not cut in situ. Mikovitch et al. (27) have mapped a nuclear matrix attachment site to the 3' $\mathrm{H} 3$ region spanned by these three sites. Putative matrix-bound topoisomerase II molecules at these sites in nuclei may be resistant to SDS-induced trapping of the cleaved state. Finally, the in vitro topoisomerase II cutting sites found 5' of H3, H2A, and H2B (22) are not observed in the SDS-induced in situ DNA cleavage reported here. These results suggest that topoisomerases in vivo bind weakly, if at all, to these hypersensitive sites. 
The ubservations that nuclei must be prepared rapidly in order to detect the specific SDS-Mg ${ }^{++}$-induced cleavage at hypersensitive sites (see Materials and Methods) and that SDS-induced cleavage is at a maximum at the earliest time point (lane 3 of Fig. 1A) suggest that the sites of cleavage reflect the genuine in situ locations of the cleaving enzyme rather than the artifatual binding of endogenous topoisomerase II molecules to adventitious recognition sites. These observations also provide an additional line of evidence against the involvement of a promiscuous endogenous nuclease.

The SDS-Mg ${ }^{++}$cleavage data indicate that topoisomerases occupy only two of the hypersensitive sites in nuclear chromatin of the histone gene cluster and therefore probably function at these sites in vivo. Topoisomerases might function at these sites to facilitate replication or, alternatively, to induce the formation of transcription complexes.

\section{ACKNOWLEDGMENTS}

We thank B. Sage and T. Landon for providing $\mathrm{Kc}$ cells and J. Lengyel for the Drosophila histone clone. This research was supported in part by grant CD-385 from the American Cancer Society.

\section{REFERENCES}

1. Gellert, M. (1981) Ann. Rev. Biochem. 50, 879-910.

2. Gellert, M. (1981) In The Enzymes, (P. Boyer, Ed.). Vol. 14, pp. 345-366. Academic Press, New York.

3. Lilly, D.M. (1984) Nature 305, 276-277.

4. Ryoji, M., and Worcel, A. (1984) Cell 37, 21-32.

5. Villeponteau, B., Lundell, M., and Martinson, H.G. (1984) Cell 39, 469-478.

6. Holm, C., Goto, T., Wang, J.C., and Botstein, D. (1985) Cell 41, 553-563.

7. Han, S., Udvardy, A., and Schedl, P. (1985) J. Mol. Biol. 183, 13-29.

8. Villeponteau, B., and Martinson, H.G. (1987) Mol. Cell. Biol. 7, 1917-1924.

9. Weintraub, H., Cheng, P.F., and Conrad, K. (1986) Cell 46, 115-122.

10. Gilmour, D.S., and Elgin, S.C.R. (1987) Mol. Cell. Biol. 7, 141-148.

11. Brill, S.J., and Sternglanz, R. (1988) Cell 54, 403-411.

12. Giaever, G.N., and Wang, J.C. (1988) Cell 55, 849-856.

13. Elgin, S.C.R. (1981) Cell 27, 413-415.

14. Larsen, A., and Weintraub, H. (1982) Cell 29, 609-622.

15. Kolwi-Shigematsu, T., Gelinas, R., and Weintraub, H. (1983) Proc. Natl. Acad. Sci. USA 80, $4389-4393$.

16. Luchnik, A.N., Bakayev, V.V., Yugai, A.A., Zbarsky, I.B., and Georgiev, G.P. (1985) Nucl. Acids Res. 13, 1135-1149.

17. Yang, L., Rowe, T.C., Nelson, E.M., and Liu, L.F. (1985) Cell 41, 127-132.

18. Morrison, A., Higgins, N.P., and Cozzarelli, N.R. (1980) J. Biol. Chem. 255,2211-2219.

19. Sander, M., and Hsieh, T.S. (1983) J. Biol. Chem. 258, 8421-8428.

20. Lui, L.F., Rowe, T.C., Yang, L., Tewey, K.M., and Chen, G.L. (1983) J. Biol. Chem. 258, $15365-15370$.

21. Sander, M., and Hsieh, T.S. (1985) Nucl. Acids Res. 13, 1057-1072.

22. Udvardy, A., Schedl, P., Sander, M., and Hsieh, T.S. (1985) Cell 40, 933-941.

23. Southern, E.M. (1975) J. Mol. Biol. 98, 503-517.

24. Villeponteau, B., and Martinson, H. (1981) Nucl. Acids Res. 9, 3731-3746.

25. Samal, B., Worcel, A., Louis, C., and Scheoll, P. (1981) Cell 23, 401-409.

26. Bonven, B.J., Gocke, E., and Westergaard, O. (1985) Cell 41, 541-551.

27. Mirkovitch, J., Mireult, M. -E., and Laemmli, U.K. (1984) Cell 39, 223-232. 